Article

\title{
Overexpression of Pear (Pyrus pyrifolia) CAD2 in Tomato Affects Lignin Content
}

\author{
Mingtong Li ${ }^{1,+}$, Chenxia Cheng ${ }^{1,+}$, Xinfu Zhang ${ }^{1} \oplus$, Suping Zhou ${ }^{2} \oplus$, Lixia Li $^{3}$ and \\ Shaolan Yang ${ }^{1, *(D)}$ \\ 1 College of Horticulture, Qingdao Agricultural University, 700 Changcheng Road, Chengyang, \\ Qingdao City 266109, China \\ 2 Department of Agricultural and Environmental Sciences, College of Agriculture, Tennessee State University, \\ 3500 John Merritt Blvd, Nashville, TN 37209, USA \\ 3 Dongying Academy of Agricultural Science, Dongying 257091, China \\ * Correspondence: shaolanyang@126.com \\ † Mingtong Li and Chenxia Cheng contributed equally to this work.
}

Received: 18 June 2019; Accepted: 16 July 2019; Published: 17 July 2019

check for updates

\begin{abstract}
P $P C A D 2$ was originally isolated from the 'Wangkumbae' pear (Pyrus pyrifolia Nakai), and it encodes for cinnamyl alcohol dehydrogenase (CAD), which is a key enzyme in the lignin biosynthesis pathway. In order to verify the function of $P p C A D 2$, transgenic tomato (Solanum lycopersicum) 'Micro-Tom' plants were generated using over-expression constructs via the agrobacterium-mediated transformation method. The results showed that the $P p C A D 2$ over-expression transgenic tomato plant had a strong growth vigor. Furthermore, these $P p C A D 2$ over-expression transgenic tomato plants contained a higher lignin content and CAD enzymatic activity in the stem, leaf and fruit pericarp tissues, and formed a greater number of vessel elements in the stem and leaf vein, compared to wild type tomato plants. This study clearly indicated that overexpressing PpCAD2 increased the lignin deposition of transgenic tomato plants, and thus validated the function of $P p C A D 2$ in lignin biosynthesis.
\end{abstract}

Keywords: P $P C A D 2$; transgenic tomato; lignin

\section{Introduction}

During the process of plant growth and development, lignin plays a key role in supporting the plant body, water transport, and resistance against external stress factors [1-4]. At some fruit postharvest storage stage, the lignin content is an important factor which can affect the fruit texture and quality. In loquat and peach fruit, lignin accumulated during the postharvest storage time, both under room temperature and $0^{\circ} \mathrm{C}$ condition $[5,6]$. In a pear cultivar of Pyrus pyrifolia, 'Whangkeumbae', hard end is a physiological disorder of the fruit. In the hard end pear fruit, lignin deposits heavily in the pericarp and pulp, leading to the formation of rough textured flesh [7].

Lignin is an amorphous, complex aromatic heteropolymer, which is produced by the phenylpropanoid metabolic pathway [8]. Lignin biosynthesis is a complex process that is divided into three main processes: the biosynthesis of monolignols, transport and polymerization [9]. The monolignols are synthesized from phenylalanine through a series of steps involving phenylalanine ammonia-lyase (PAL), cinnamate 4-hydroxylase $(\mathrm{C} 4 \mathrm{H}), 4$-coumaric acid: CoA ligase (4CL), p-coumarate 3-hydroxylase $(\mathrm{C} 3 \mathrm{H})$, hydroxycinnamoyl: CoA transferase (HCT), caffeoyl-CoA O-methyltransferase (CCoAOMT), cinnamoyl-CoA reductase (CCR), ferulate 5-hydroxylase (F5H), Caffeic acid $O-$ methyltransferase (COMT), and cinnamyl alcohol dehydrogenase (CAD) [10]. After these steps, monolignols are transported to the apoplast [9]. The monolignols, including p-coumaryl, 
coniferyl and sinapyl alcohols, are the main building blocks of lignin [2]. Lignin units are polymerized with the monolignols (sinapyl alcohol, S unit; coniferyl alcohol, $\mathrm{G}$ unit; and p-coumaryl alcohol, $\mathrm{H}$ unit) by peroxidase (POD) and laccase (LAC) [10-12]. Gymnosperm lignins consist of $G$ units that only have low levels of $\mathrm{H}$ units, and dicotyledonous angiosperm lignins are composed principally of $\mathrm{G}$ and $\mathrm{S}$ units $[2,10]$.

CAD is a multifunctional enzyme that catalyses the final step in the biosynthesis of monolignols, converting cinnamaldehydes into the corresponding alcohols [2,13]. Related studies have shown that the CAD activity affects not only the content, but also the type of lignin monomer [14]. In our previous work, we have cloned genes of PpPAL1, PpPAL2, Pp4CL1,Pp4CL2, PpCAD1, PpCAD2, PpPOD1, PpPOD2, PpPOD3 and PpPOD4, and analyzed their expression patterns in hard end pear fruit $[7,15]$. The transcript levels of $P p C A D 2$ were found to have a positive correlation with lignin accumulation in the hard end 'Whangkeumbae' pear; the application of calcium chloride alleviated the hard end phenomenon, while simultaneously suppressing the expression of the gene [7]. Studies using transgenic tobacco, poplar, alfalfa, arabidopsis and maize also provided experimental evidences showing that CADs participate in the biosynthesis of the lignin monomer [16-25].

Genetic transformation is a key technology for gene functional verification. For perennial fruit trees, it is hard to carry on the transgenic technology due to the lengthy generation cycles and the difficulty in regenerating in vitro [26]. The agrobacterium-mediated transformation of 'Micro-Tom' has been reported in the functional studies of various genes [27-29]. The use of tomato to transfer heterogeneous genes from fruit trees, followed by the physiological characterization of the transgenic plants, will greatly reduce the amount of time required to validate the gene function using the fruit tree system. The tomato (Solanum lycopersicum) is used as a model plant of the Solanaceae family. A miniature tomato cultivar of S. lycopersicum, 'Micro-Tom', being an excellent model system, has some characteristics that include a small size, short generation time and a transformable quality, that make it suitable for experimental research $[27,30,31]$. Recent studies have reported that the cell wall stiffness of tomato fruit skin is mediated by lignin biosynthesis [32-34]. It has been reported that inhibiting the lignification of the pericarp may contribute to fleshy fruit during tomato fruit ripening [35]. A MADS-box transcription factor gene, TOMATO AGAMOUS-LIKE 1 (TAGL1) controls the lignification of tomato fruit [32]. In TAGL1-silenced fruit pericarp, lignin pathway genes, such as $P A L, 4 C L$ and $C A D$, are up-regulated, and the lignin content is also increased [32].

In our current study, transgenic tomato 'Micro-Tom' plants harboring P $P C A D 2$ constructs were generated via the agrobacterium-mediated transformation method. In transgenic tomato plants, the physiological properties and the expression level of $P p C A D 2$ were analyzed to clarify the role of $P p C A D 2$ in lignin synthesis.

\section{Results and Discussion}

\subsection{Generation of Transgenic Tomato Plants}

To investigate the function of $P p C A D 2$, we isolated a 978-bp predicted opening reading frame, encoding a protein of 325 amino acids with a cinnamyl-alcohol dehydrogenase domain (Figure S1). We next overexpressed (OX) PpCAD2 in tomato. Healthy 'Micro-Tom' plants were generated, and these plants were propagated in vitro. The rooted plants were transplanted into pots (Figure S2). The positive overexpressed transgenic tomato lines were confirmed by polymerase chain reaction (PCR) analysis using DNA extracted from mature leaves (Figure S3). Fifteen independent transgenic lines were obtained. Among these, 11 independent lines were selected for RNA extraction. We also evaluated the expression of $P p C A D 2$ in the PpCAD2--ox lines through a qRT-PCR analysis. Compared with the wild type (WT) plant, the three PpCAD2-ox (\#5,\#6 and \#12) lines exhibited a higher expression of PpCAD2 (Figure 1B). The three PpCAD2--ox (\#5, \#6 and \#12) lines were chosen for the functional analysis (Figure $1 \mathrm{~A}, \mathrm{~B})$. 

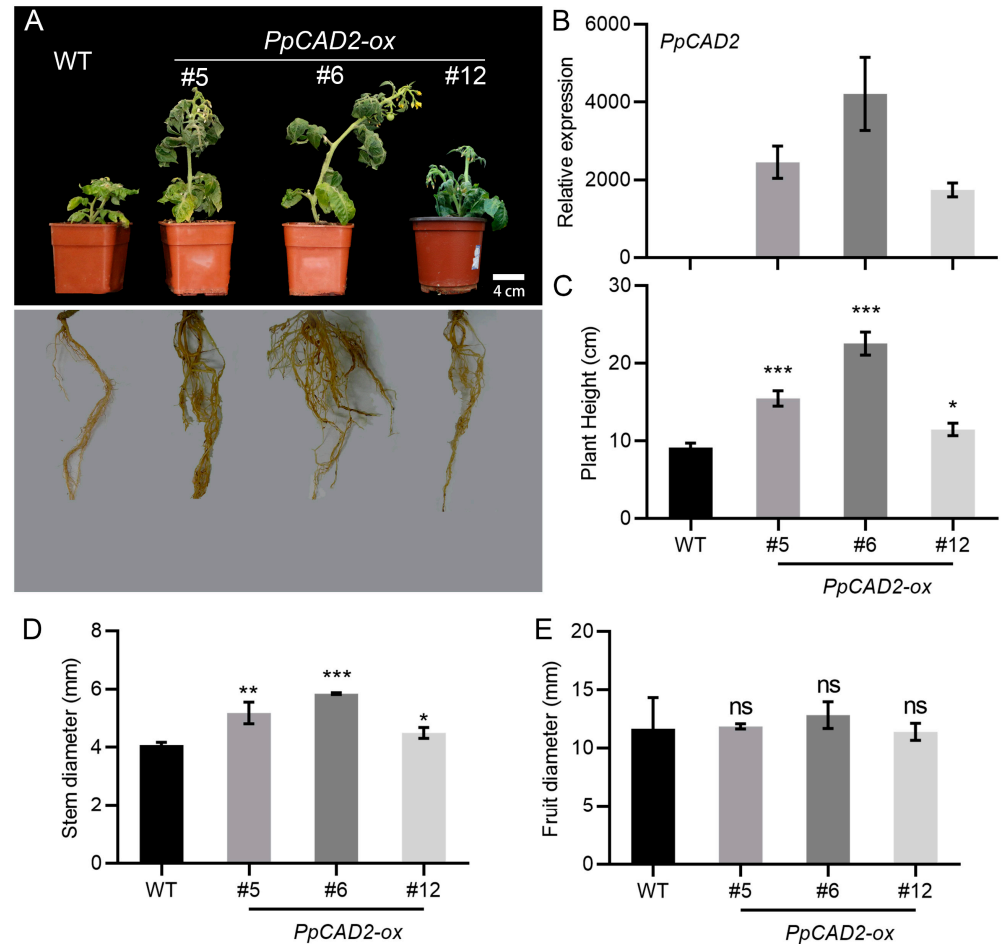

Figure 1. Phenotype analysis of non-transgenic (WT) and PpCAD2-overexpressing (PpCAD2-ox) transgenic tomato lines. (A) Photographs of the morphology in the WT and transgenic lines; (B) The relative expression level of $P p C A D 2$ in the WT and transgenic plants; (C) The plant height of the WT and transgenic plants; (D) The stem diameter the WT and transgenic plants; (E) The fruit diameter of the WT and transgenic plants. In all cases, the data represent the mean \pm SD (standard deviation) from three biological replicates. Significant differences between the wild-type and transgenic plants are indicated $\left({ }^{*} P<0.05,{ }^{* *} P<0.01,{ }^{* * *} P<0.001\right.$, Student's $t$-test $)$.

\subsection{The Morphology Indexes of Transgenic Plants Overexpressing PpCAD2}

We compared the morphology of the plants from the WT and the PpCAD2-ox lines. Compared with the WT plants, the overexpression of $P p C A D 2$ resulted in taller plants with a more extensive root system (Figure 1A). The WT plants only had a fewer and shorter roots (Figure 1A). The plant height in the PpCAD2-ox lines was significantly higher than for the WT plants (Figure 1C). Like the plant height, the stem diameter in the PpCAD2-ox lines was significantly larger than for the WT plants (Figure 1D). However, overexpression of $P p C A D 2$ did not affect the fruit diameter (Figure 1E). In agreement with our results, in Arabidopsis, the silencing of $C A D C$, and $C A D D$ resulted in a severe dwarf phenotype [36]. Moreover, it has been reported that Medicago truncatula CAD1 mutant cad1-1 plants exhibit a dwarf phenotype when grown at $30^{\circ} \mathrm{C}$ [37]. In rice, $C A D$ mutant plants also exhibit a semi-dwarf phenotype [38]. Collectively, these results suggest that $P p C A D 2$ functions by increasing the plant height and stem diameter but not by affecting the fruit diameter.

\subsection{Overexprssion of PpCAD2 in Tomato Increased the Lignin Content and CAD Enzymatic Activity in Stem}

The CAD enzyme has been reported to have a key role during the lignin biosynthesis. To determine whether $P p C A D 2$ regulates the lignin content, we examined the degree of lignification and lignin content in wild-type and $P p C A D 2-o x$ stems. The Weisner staining results showed that the level of the stem's lignin staining was higher in the PpCAD2-ox lines than in the WT plants (Figure 2A). Overexpression of $P p C A D 2$ results in more cell layers of xylem elements and a wider xylem tissue (Figure 2B). Observations of autofluorescence also showed that there are more cell layers of xylem elements in the stem of the $P p C A D 2-o x$ lines than for the wild type plants (Figure 2B). Then, we examined the lignin content and CAD enzymatic activity in the stem of the WT and PpCAD2-ox lines. The lignin content of the stem 
in the transgenic lines overexpressing P $p C A D 2$ was significantly higher than that in WT (Figure 2C). As expected, the CAD enzymatic activity was significantly higher in the PpCAD2-ox lines than for WT (Figure 2D). These results further indicate that the CAD enzymatic activity is positively correlated with the lignin content in the stem. Overexpression of $P p C A D 2$ increased the level of lignification of the stem tissues, suggesting that P $p C A D 2$ may play a role in lignin accumulation in tomato stem tissues.
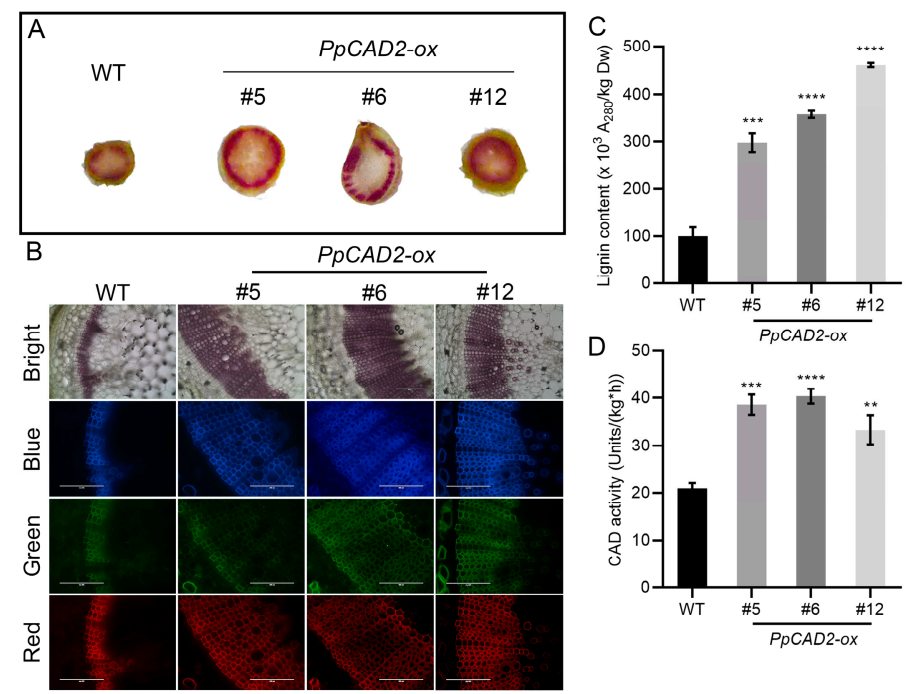

Figure 2. $P p C A D 2$ increases the lignin content and the cinnamyl alcohol dehydrogenase (CAD) enzyme activity in the stem of transgenic tomato plants. (A) Transverse sections of the stem were stained with phloroglucinol-HCl for the detection of lignin; (B) Autofluorescence of the stem's transverse slice. Bright: bright field images, Blue: blue autofluorescence, Green: green autofluorescence, Red: red autofluorescence. Scale bars $=200 \mu \mathrm{m}$; (C) The lignin content of the stem in the WT and transgenic plants; (D) The CAD enzyme activity in the stem of WT and transgenic plants. In (C) and (D), the data represent the mean \pm SD (standard deviation) from three biological replicates. Significant differences between the wild-type and transgenic plants are indicated $\left({ }^{* *} P<0.01,{ }^{* *} P<0.001,{ }^{* * * *} P<0.0001\right.$, Student's t-test).

\subsection{Overexpression of P $p C A D 2$ in Tomato Increased the Lignin Content in Fruit Pericarp and Leaf}

In our previous study, we have proven that CAD is involved in regulating lignin biosynthesis in pear flesh [7]. Previous research had reported that the lignin content could be measured in the pericarp of fruit during tomato fruit ripening [35]. In tomato, the fruit with a higher expression level of the lignin pathway genes, such as PAL, $4 C L$ and $C A D$, had a higher lignin content in the fruit pericarp [32]. To determine the change of the lignin content and CAD activity in the fruit pericarp of transgenic plants, the lignin content and CAD activity were measured. The CAD activity in the fruit pericarp of the PpCAD2-ox lines was significantly higher than that of the WT plants (Figure 3A). Similarly, the lignin content of the PpCAD2-ox lines was significantly higher than that of the WT plants (Figure 3B). These data suggest that overexpression of P $P C A D 2$ in tomato increases the CAD activity and the lignin content of the fruit pericarp.

The degree of lignification in leaf veins was also examined in transgenic plants overexpressing P $p C A D 2$. Observations of autofluorescence showed that, similar to the stems, PpCAD2 transgenic plants had increased layers of xylem elements compared with WT (Figure 4A). In addition, the diameter of the xylem elements was also larger in the PpCAD2-ox lines. As with the data in the stem and fruit pericarp, both the lignin content and CAD activity in the leaf veins of the PpCAD2-ox plants were significantly higher than those of WT (Figure 4B,C), indicating that overexpression of PpCAD2 improved the CAD enzyme activity, which in turn enhances the degree of lignification in transgenic tomato leaves. 

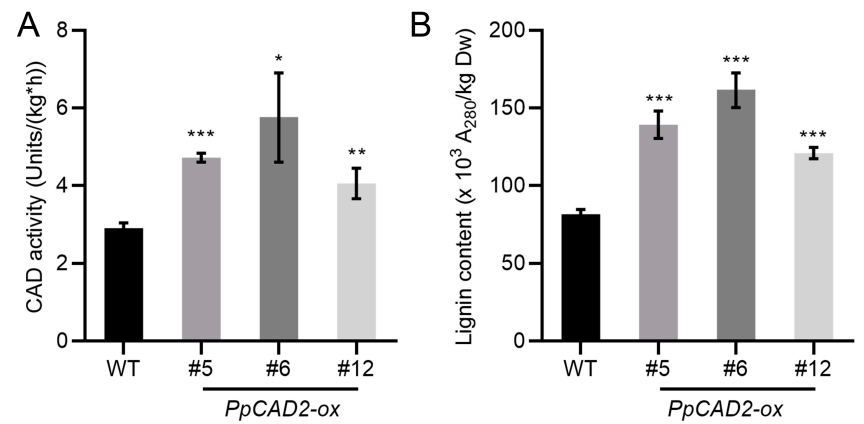

Figure 3. $P p C A D 2$ increases the lignin content and CAD enzyme activity in the fruit pericarp of transgenic tomato plants. (A) The lignin content of the fruit pericarp in the WT and transgenic plants; (B) The CAD enzyme activity in the fruit pericarp of the WT and transgenic plants. In (A) and (B), the data represent the mean \pm SD (standard deviation) from three biological replicates. Significant differences between the wild-type and transgenic plants are indicated ${ }^{*} P<0.05,{ }^{* *} P<0.01,{ }^{* * *} P<$ 0.001 , Student's t-test).

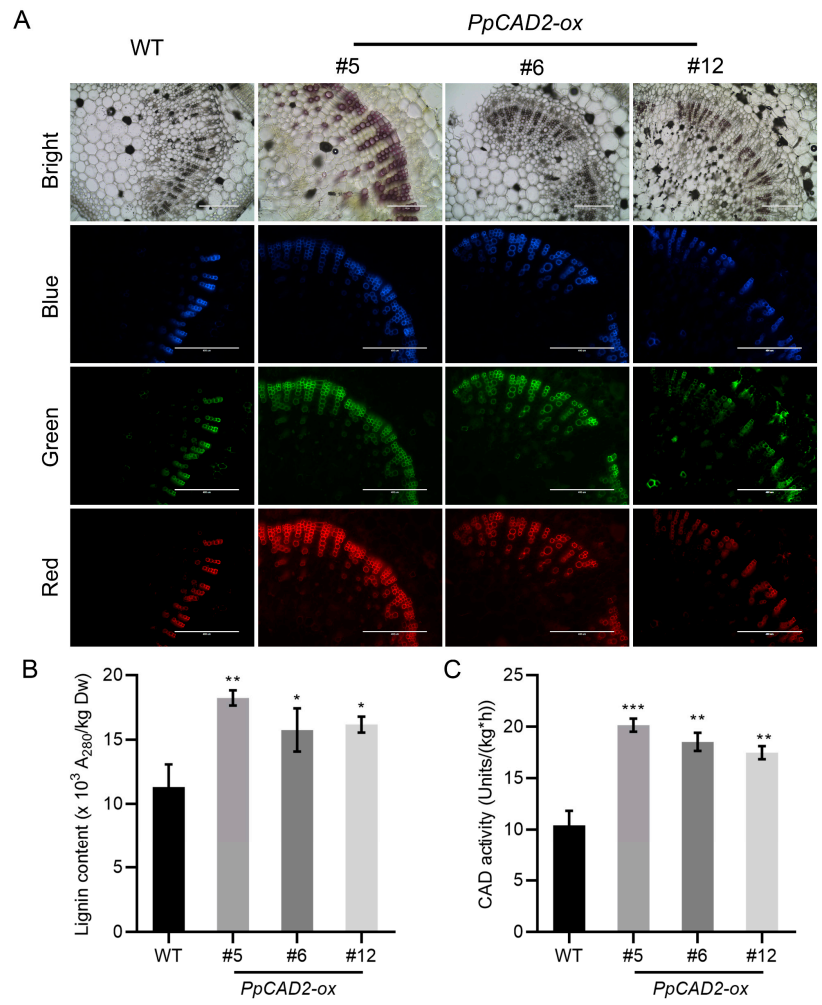

Figure 4. $P p C A D 2$ increases the lignin content and CAD enzyme activity in the leaves of transgenic tomato plants. (A) Autofluorescence of transverse slice in the leaf veins, Bright: bright field images, Blue: blue autofluorescence, Green: green autofluorescence, Red: red autofluorescence. Scale bars $=200 \mu \mathrm{m}$; (B) The lignin content of leaves in the WT and transgenic plants; (C) The CAD enzyme activity in the leaves of WT and transgenic plants. In (B) and (C), the data represent the mean \pm SD (standard deviation) from three biological replicates. Significant differences between the wild-type and transgenic plants are indicated $\left({ }^{*} P<0.05,{ }^{* *} P<0.01,{ }^{* * *} P<0.001\right.$, Student's $t$-test $)$.

$C A D$ genes were demonstrated to control lignification in plants [39-41]. In agreement with our results, Brachypodium distachyon $C A D$ gene $B d C A D 1$ mutants displayed a reduced CAD activity and lower lignin content [39], suggesting that the CAD activity is positively correlated with the lignin content. In Brassica chinensis, the induced expression of $B c C A D 1-1$ and $B c C A D 2$ could increase the 
lignification of stems [40]. $A a C A D$ has also been reported to positively enhance lignin formation in Artemisia annua [41]. In summary, these results support that $P p C A D 2$ positively regulates lignin biosynthesis by increasing the CAD activity in the stems, fruit pericarp and leaves of transgenic tomato plants. In pear, the lignin content and the expression level of $P p C A D 2$ were positively correlated with the occurrence of fruit with hard end [7]. From the above results, we infer that the down-regulation of $P p C A D 2$ expression could appropriately inhibit the formation of fruit hard end by decreasing the lignin content. Further investigations to clarify the role of $P p C A D 2$ in the occurrence of fruit with hard end and to determine the upstream regulatory factor of $P p C A D 2$ will provide a better mechanistic understanding of the formation of fruit with hard end.

\section{Materials and Methods}

\subsection{Plant Material}

Tomato (S. lycopersicum) 'Micro-Tom' seeds were disinfected by submerging in $75 \%$ ethanol for 2 min followed by $10 \%$ sodium hypochlorite for $10 \mathrm{~min}$. After three rinses with sterile water and being blotted dry of the excess water on the seed surface, the seeds were inoculated on a Murashige and Skoog (MS) medium. The cultures were kept in the dark and transferred to light conditions when cotyledons emerged [42,43].

\subsection{Vector Construction and Tomato Transformation}

The primers with restriction enzymes sites were designed using DNAStar software (Lasergene). $P p C A D 2$ over-expression primers, forward: 5'CGTCTAGAAGATGAGCAGCGGAGCAG (Xba I) 3', reverse: 5' CCGGATCCAAGGGAAGCCGGAGTTTA (BamH I) 3'. The full-length cDNA of PpCAD2 was ligated into a cloning vector $\mathrm{pMD19-T}$. To prepare the $P p C A D 2$ over-expression (35S::PpCAD2) constructs, plasmids were isolated and digested with the restriction enzymes $\mathrm{BamH}$ I and $\mathrm{Xba}$ I. The insert fragment was isolated and then cloned onto a vector, pBI121, under a $35 \mathrm{~S}$ promoter. These constructs were transformed into Agrobacterium tumefaciens EHA105 through the freeze-thaw method separately [44].

For the overexpression, cotyledons of 'Micro-Tom' were transformed by an Agrobacterium-mediated transformation. The cotyledons of 'Micro-Tom' were sectioned to $3 \mathrm{~mm}^{2}$, and one hundred cotyledon explants were dipped into a bacterial suspension $\left(\mathrm{OD}_{600}=0.3-0.4\right)$ of $A$. tumefaciens EHA105 harboring the transformation constructs. After $5 \mathrm{~min}$, the explants were blotted dry with autoclaved filter paper. The explants were placed back onto the co-cultivation medium and incubated in the dark for $1.5 \mathrm{~d}$ under $28{ }^{\circ} \mathrm{C}$. The explants were transferred to a callus induction/selection medium containing MS salts, $3 \%$ sucrose, $1.5 \mathrm{mg} \cdot \mathrm{L}^{-1}$ zeatin, $50 \mathrm{mg} \cdot \mathrm{L}^{-1}$ kanamycin and $500 \mathrm{mg} \cdot \mathrm{L}^{-1} \mathrm{Cef}$, and $0.7 \%$ agar at $\mathrm{pH} 5.8$ [41]. The explants were transferred onto a fresh medium every 2 weeks. When adventitious buds developing from the callus grew to about $3 \mathrm{~cm}$ tall, they were dissected and transferred to a new conical flask containing a shoot elongation medium containing MS salts, $3 \%$ sucrose, $1.0 \mathrm{mg} \cdot \mathrm{L}^{-1} 6$-Benzylaminopurine (6-BA), $0.1 \mathrm{mg} \cdot \mathrm{L}^{-1}$ Indole-3-Butytric acid (IBA) and $0.7 \%$ agar. The shoots forming a few leaves were transferred to a rooting medium containing MS salts, $3 \%$ sucrose, $0.2 \mathrm{mg} \cdot \mathrm{L}^{-1} \mathrm{IBA}$ and $0.7 \%$ agar. The rooted plants were transplanted to pots and grown in a growth chamber that was programmed at a constant temperature of $21^{\circ} \mathrm{C}$ and a 16-h-light/8-h-dark cycle. Wild type (WT) plants were propagated concurrent to the transgenic plants.

\subsection{PCR Analysis and Gene Expression Analysis}

Genomic DNA was extracted from 'Micro-Tom' leaves using a plant total DNA extract kit (TianGen, Shanghai, China). The PCR amplification used primer pairs of PpCAD2 forward: 5'-CGTCTAGAAGTAGAGCAGCGGAGCAG-3', and PpCAD2 reverse: 5'-CCGGAT CCAAGGGAAGCCGGAGTTTA-3'. 
Total RNA was extracted from the 'Micro-Tom' leaf tissue using EASYspin Plant RNA Kit (Yuanpinghao, China) according to the manufacturer's instructions. Genomic DNA was removed by DNase. cDNA was synthesized with reverse transcription using the Prime Script ${ }^{\mathrm{TM}} \mathrm{RT}$ reagent Kit (Takara, Dalian, China) according to the manufacturer's instruction and was used as the template for the qPCR analysis. qPCR was performed on a Light Cycler $₫ 480$ instrument (Roche, Basel, Switzerland). The procedure included annealing at $94^{\circ} \mathrm{C}$ for $5 \mathrm{~min}$, followed by 40 cycles of $94{ }^{\circ} \mathrm{C}$ for $15 \mathrm{~s}, 60^{\circ} \mathrm{C}$ for 1 $\mathrm{min}$, and $72{ }^{\circ} \mathrm{C}$ for $30 \mathrm{~s}$. A tomato actin gene was used for normalization. The primers used for the qPCR analysis, listed in Table 1, were designed using Primer 3 (http://bioinfo.ut.ee/primer3-0.4.0/). The relative gene expression level was calculated using the $2^{-\Delta \Delta C t}$ method [45]. Three biological replicates were performed for each sample.

Table 1. Primers used for the q-PCR analysis.

\begin{tabular}{cccc}
\hline Gene Name & Gene ID & Primer Name & Primer Sequence (5' to $\mathbf{3}^{\prime}$ ) \\
\hline \multirow{2}{*}{ PpCAD2 } & KJ577637 & PpCAD2-F & TTTGGTTGAGAGAGTTGCCCAC \\
& & PpCAD2-R & ATTCGACACCCAAGCTCTTCG \\
SlActin & LOC101264618 & SlActin-F & CAGATGTGGATAACGAAGGCC \\
& SlActin-R & TCACAGTAGAAAGACCTGAACAA \\
\hline
\end{tabular}

\subsection{Lignin Content Determination}

The lignin content of the stem, leaf and fruit pericarp in the three-month-old 'Micro-Tom' tomato was measured according to the method described by Dyckmans [46]. Frozen tissue powder (200 mg) was suspended in $10 \mathrm{~mL}$ of washing buffer $\left(100 \mathrm{mM} \mathrm{K}_{2} \mathrm{HPO}_{4} / \mathrm{KH}_{2} \mathrm{PO}_{4}, 0.5 \%\right.$ Triton X-100, 0.5\% PVP, $\mathrm{pH} 7.8$ ) for $30 \mathrm{~min}$. After being centrifuged, the pellet was washed twice (30 min) in $100 \% \mathrm{MeOH}$. Then, the resulting pellet was dried in $80^{\circ} \mathrm{C}$ overnight. The dried pellet was added with $1 \mathrm{~mL} 2 \mathrm{M} \mathrm{HCl}$ and $0.1 \mathrm{~mL}$ thioglycolic acid, then put into boiling water for 4 hours. The obtained end product was dissolved in $1 \mathrm{~mL} 1 \mathrm{M} \mathrm{NaOH}$. The diluted samples were assayed for absorbance at $280 \mathrm{~nm}$, and $\mathrm{NaOH}$ was used as a blank. All measurements were performed in biological triplicates.

\subsection{Determination of Biomass Parameters}

The plant height of the three-month-old 'Micro-Tom' tomato was measured with a ruler. Additionally, the stem diameter and mature fruit diameter were measured with a vernier caliper. Three biological replications were determined.

\subsection{CAD Enzyme Activity}

The stem and fruit CAD enzymatic activity was measured according to the method described by Cai [47]. The samples were grinded with $10 \mathrm{~mL}$ Tris: $\mathrm{HCl}$ buffer $(200 \mathrm{mM}, \mathrm{pH}$ 7.5). The reaction mixture contained $50 \mu \mathrm{L}$ of extract, $1 \mathrm{~mL}$ of $100 \mathrm{mM}$ Tris: $\mathrm{HCl}$ buffer (pH 8.8), $1 \mathrm{~mL}$ of $20 \mathrm{mM}$ coniferyl alcohol and $1 \mathrm{~mL}$ of $5 \mathrm{mM}$ NADP+. The mixture was put at $37^{\circ} \mathrm{C}$ during $2 \mathrm{~min}$ for the reaction, after which $0.5 \mathrm{~mL} 1 \mathrm{~mol} \cdot \mathrm{L}^{-1} \mathrm{HCl}$ was added to terminate the reaction. The samples were assayed for absorbance at $400 \mathrm{~nm}$. The data were expressed on a protein basis, and the analysis was biologically repeated three times.

\subsection{Weisner Staining and Microscopy}

The transverse section of the leaf veins and stem were used by Weisner staining and microscopy. Weisner reagent (phloroglucinol/ $\mathrm{HCl}$ ) was used to stain the plant tissue for 5 min before it was visualized for lignification under a microscope [48]. The lignified structures appeared pink or fuchsia in the bright field images. Auto-fluorescence within the leaf and stem sections was also observed with the aid of an EVOS smart fluorescence microscope (Thermo Fisher, Waltham, MA, America). 


\section{Conclusions}

In this study, overexpression of $P p C A D 2$ in transgenic tomato plants increased the plant height and stem diameter. Furthermore, overexpression of $P p C A D 2$ increased the lignin content in the stems, leaves and fruit pericarp tissues, partially by increasing the CAD enzyme activity, which was an important enzyme in the biosynthesis of monolignols. Overexpression of PpCAD2 also increased the size of the vessel element in the xylem tissues. Our data suggest that the $P p C A D 2$ functions by positively regulating the degree of lignification.

Supplementary Materials: Figure S1: PpCAD2 sequence analysis, Figure S2: Generation of transgenic tomato 'Micro-Tom', Figure S3: PCR identification of transgenic 'Micro-Tom' plants with the PpCAD2 constructs.

Author Contributions: S.Y. and X.Z. conceived and designed the experiments, M.L. and C.C. performed the experiments and analyzed the data, S.Z. and S.Y. wrote the manuscript, L.L. analyzed the partial data. All authors read and approved the manuscript.

Funding: This work was supported by the Project of Shandong Natural Science Foundation (ZR2017MC006), the Project of Shandong Modern Vegetable Technology Industry System (SDAIT-05-21).

Acknowledgments: The authors would like to acknowledge all the financial supports and all the participating experts. The authors also acknowledge the technical support for the Central Laboratory of Qingdao Agricultural University.

Conflicts of Interest: The authors declare no conflict of interest.

\section{References}

1. Boudet, A.M.; Kajita, S.; Grima-Pettenati, J.; Goffner, D. Lignins and lignocellulosics: A better control of synthesis for new and improved uses. Trends Plant Sci. 2003, 8, 576-581. [CrossRef]

2. Boerjan, W.; Ralph, J.; Baucher, M. Lignin biosynthesis. Annu. Rev. Plant Biol. 2003, 54, 519-546. [CrossRef]

3. Peter, G.; Neale, D. Molecular basis for the evolution of xylem lignification. Curr. Opin. Plant Biol. 2004, 7 , 737-742. [CrossRef]

4. $\quad$ Dauwe, R.; Morreel, K.; Goeminne, G.; Gielen, B.; Rohde, A.; Van Beeumen, J.; Ralph, J.; Boudet, A.M.; Kopka, J.; Rochange, S.F.; et al. Molecular phenotyping of lignin-modified tobacco reveals associated changes in cell-wall metabolism, primary metabolism, stress metabolism and photorespiration. Plant J. 2007, 52, 263-285. [CrossRef]

5. Wang, Y.; Zhang, X.; Yang, S.; Yuan, Y. Lignin involvement in programmed changes in peach-fruit texture indicated by metabolite and transcriptome analyses. J. Agric. Food Chem. 2018, 66, 12627-12640. [CrossRef]

6. Ge, H.; Zhang, J.; Zhang, Y.J.; Li, X.; Yin, X.R.; Grierson, D.; Chen, K.S. EjNAC3 transcriptionally regulates chilling-induced lignification of loquat fruit via physical interaction with an atypical CAD-like gene. J. Exp. Bot. 2017, 68, 5129-5136. [CrossRef]

7. Lu, G.L.; Li, Z.J.; Zhang, X.F.; Wang, R.; Yang, S.L. Expression analysis of lignin associated genes in hard end pear (Pyrus pyrifolia Whangkeumbae) and its response to calcium chloride treatment conditions. Plant Growth Regul. 2015, 34, 251-262. [CrossRef]

8. Uraki, Y.; Koda, K. Encyclopedia of Polymeric Nanomaterials; Springer: Berlin/Heidelberg, Germany, 2015; pp. 1073-1080.

9. Liu, Q.; Luo, L.; Zheng, L. Lignins: Biosynthesis and biological functions in plants. Int. J. Mol. Sci. 2018, 19, 335. [CrossRef]

10. Vanholme, R.; Demedts, B.; Morreel, K.; Ralph, J.; Boerjan, W. Lignin biosynthesis and structure. Plant Physiol. 2019, 153, 895-905. [CrossRef]

11. Alejandro, S.; Lee, Y.; Tohge, T.; Sudre, D.; Osorio, S.; Park, J.; Bovet, L.; Lee, Y.; Geldner, N.; Fernie, A.R.; et al. AtABCG29 is a monolignol transporter involved in lignin biosynthesis. Curr. Biol. 2012, 22, 1207-1212. [CrossRef]

12. Liu, C.J.; Miao, Y.C.; Zhang, K.W. Sequestration and transport of lignin monomeric precursors. Molecules 2011, 16, 710-727. [CrossRef]

13. Li, L.; Popko, J.L.; Umezawa, T. 5-Hydroxyconifery aldehyde modulates enzymatic methylation for syringyl monolingnol formation a new view of monolingnol biosythensis in angiosperms. J. Biol. Chem. 2000, 275, 6539-6545. [CrossRef] 
14. Campbell, M.M.; Sederoff, R.R. Variation in lignin content and composition (mechanisms of control and implications for the genetic improvement of plants). Plant Physiol. 1996, 110, 3-13. [CrossRef]

15. Yang, S.L.; Zhang, X.N.; Lu, G.L.; Wang, C.R.; Wang, R. Regulation of gibberellin on gene expressions related with the lignin biosynthesis in 'Wangkumbae' pear (Pyrus pyrifolia Nakai) fruit. Plant Growth Regul. 2015, 76, 127-134. [CrossRef]

16. Eudes, A.; Sathitsuksanoh, N.; Baidoo, E.E.; George, A.; Liang, Y.; Yang, F.; Singh, S.; Keasling, J.D.; Simmons, B.A.; Loque, D. Expression of a bacterial 3-dehydroshikimate dehydratase reduces lignin content and improves biomass saccharification efficiency. Plant Biotechnol. J. 2015, 13, 1241-1250. [CrossRef]

17. Halpin, C.; Knight, M.E.; Foxon, G.A.; Campbell, M.M.; Boudet, A.M.; Boon, J.J.; Chabbert, B.; Tollier, M.T.; Schuch, W. Manipulation of lignin quality by downregulation of cinnamyl alcohol dehydrogenase. Plant J. 1994, 6, 339-350. [CrossRef]

18. Hibino, T.; Takabe, K.; Kawazu, T.; Shibata, D.; Higuchi, T. Increase of cinnamaldehyde groups in lignin of transgenic tobacco plants carrying an antisense gene for cinnamyl alcohol dehydrogenase. Biosci. Biotechnol. Biochem. 1995, 59, 929-931. [CrossRef]

19. Stewart, D.; Yahiaoui, N.; McDougall, G.J.; Myton, K.; Marque, C.; Boudet, A.M.; Haigh, J. Fourier-transform infrared and Raman spectroscopic evidence for the incorporation of cinnamaldehydes into the lignin of transgenic tobacco (Nicotiana tabacum L.) plants with reduced expression of cinnamyl alcohol dehydrogenase. Planta 1997, 201, 311-318. [CrossRef]

20. Damiani, I.; Morreel, K.; Danoun, S.; Goeminne, G.; Yahiaoui, N.; Marque, C.; Kopka, J.; Messens, E.; Goffner, D.; Boerjan, W.; et al. Metabolite profling reveals a role for atypical cinnamyl alcohol dehydrogenase CAD1 in the synthesis of coniferyl alcohol in tobacco xylem. Plant Mol. Biol. 2005, 59, 753-769. [CrossRef]

21. Baucher, M.; Chabbert, B.; Pilate, G.; Van, D.J.; Tollier, M.T.; Petit-Conil, M.; Cornu, D.; Monties, B.; Van, M.M.; Inzé, D.; et al. Red xylem and higher lignin extractability by down-regulating a cinnamyl alcohol dehydrogenase in poplar (Populus tremula x P. alba). Plant Physiol. 1996, 112, 1479-1490. [CrossRef]

22. Eudes, A.; Pollet, B.; Sibout, R.; Do, C.T.; Séguin, A.; Lapierre, C.; Jouanin, L. Evidence for a role of AtCAD 1 in lignification of elongating stems of Arabidopsis thaliana. Planta 2006, 225, 23-39. [CrossRef]

23. Halpin, C.; Holt, K.; Chojecki, J.; Oliver, D.; Chabbert, B.; Monties, B.; Edwards, K.; Barakate, A.; Foxon, G.A. Brown-midrib maize (bm1)-A mutation affecting the cinnamyl alcohol dehydrogenase gene. Plant J. 1998, 14, 545-553. [CrossRef]

24. Baucher, M.; Bernard-Vailhé, M.A.; Chabbert, B.; Besle, J.M.; Opsomer, C.; Van, M.M.; Botterman, J. Down-regulation of cinnamyl alcohol dehydrogenase in transgenic alfalfa (Medicago sativa L.) and the impact on lignin composition and digestibility. Plant Mol. Biol. 1999, 39, 437-447. [CrossRef]

25. Wang, Y.L.; Zhang, X.F.; Yang, S.L. Heterogenous expression of Pyrus pyrifolia PpCAD2 and PpEXP2 in tobacco impacts lignin accumulation in transgenic plants. Gene 2017, 637, 181-189. [CrossRef]

26. Borejsza-Wysocka, E.; Norelli, J.L.; Aldwinckle, H.S.; Malnoy, M. Stable expression and phenotypic impact of attacin E transgene in orchard grown apple trees over a 12 year period. BMC Biotechnol. 2010, 10, 41. [CrossRef]

27. Meissner, R.; Jacobson, Y.; Melamed, S.; Levyatuv, S.; Ashri, A.; Elkind, Y.; Levy, A.; Shalev, G. A new model system for tomato genetics. Plant J. 1997, 12, 1465-1472. [CrossRef]

28. Meissner, R.; Chagué, V.; Zhu, Q.; Emmanuel, E.; Elkind, Y.; Levy, A.A. A high throughput system for transposon tagging and promoter trapping in tomato. Plant J. 2000, 22, 265-274. [CrossRef]

29. Mathews, H.; Clendennen, S.K.; Caldwell, C.G.; Liu, X.L.; Connors, K.; Matheis, N.; Schuster, D.K.; Menasco, D.J.; Wagoner, W.; Lightner, J.; et al. Activation tagging in tomato identifies a transcriptional regulator of anthocyanin biosynthesis, modification, and transport. Plant Cell 2003, 15, 1689-1703. [CrossRef]

30. Shibata, D. Genome sequencing and functional genomics approaches in tomato. J. Gen. Plant Pathol. 2005, 71, 1-7. [CrossRef]

31. Aoki, K.; Yano, K.; Suzuki, A.; Kawamura, S.; Sakurai, N.; Suda, K.; Kurabayashi, A.; Suzuki, T.; Tsugane, T.; Watanabe, M.; et al. Large-scale analysis of full-length cDNAs from the tomato (Solanum lycopersicum) cultivar Micro-Tom, a reference system for the Solanaceae genomics. BMC Genom. 2010, 11, 210. [CrossRef]

32. Giménez, E.; Pineda, B.; Capel, J.; Antón, M.T.; Atarés, A.; Pérez-Martín, F.; Garcia-Sogo, B.; Angosto, T.; Moreno, V.; Lozano, R. Functional analysis of the Arlequin mutant corroborates the essential role of the ARLEQUIN/TAGL1 gene during reproductive development of tomato. PLoS ONE 2010, 5, e14427. [CrossRef] 
33. Edmondson, R.N.; Andrews, J.; Adams, S.R.; Burton, K.S. Partial purification of tomato fruit peroxidase and its effect on the mechanical properties of tomato fruit skin. J. Exp. Bot. 2002, 53, 2393-2399.

34. Quiroga, M. A tomato peroxidase involved in the synthesis of lignin and suberin. Plant Physiol. 2000, 122, 1119-1128. [CrossRef]

35. Garceau, D.C.; Batson, M.K.; Pan, I.L. Variations on a theme in fruit development: The PLE lineage of MADS-box genes in tomato (TAGL1) and other species. Planta 2017, 246, 313-321. [CrossRef]

36. Thevenina, J.; Polleta, B.; Letarneca, B.; Saulnierb, L.; Gissotc, L. The simultaneous repression of CCR and CAD, two enzymes of the lignin biosynthetic pathway, results in sterility and dwarfism in Arabidopsis Thaliana. Mol. Plant 2011, 4, 70-82. [CrossRef]

37. Zhao, Q.; Tobimatsu, Y.; Zhou, R.; Pattathil, S.; Gallego-Giraldo, L.; Fu, C.; Jackson, L.A.; Hahn, M.G.; Kim, H.; Chen, F.; et al. Loss of function of cinnamyl alcohol dehydrogenase 1 leads to unconventional lignin and a temperature-sensitive growth defect in Medicago truncatula. Proc. Natl. Acad. Sci. USA 2013, 110, 13660-13665. [CrossRef]

38. Li, X.J.; Yang, Y.; Yao, J.L.; Chen, G.X.; Li, X.H.; Zhang, Q.F.; Wu, C.Y. FLEXIBLE CULM 1 encoding a cinnamyl-alcohol dehydrogenase controls culm mechanical strength in rice. Plant Mol. Biol. 2009, 69, 685-697. [CrossRef]

39. Bouvier d'Yvoire, M.; Bouchabke-Coussa, O.; Voorend, W.; Antelme, S.; Cézard, L.; Legée, F.; Lebris, P.; Legay, S.; Whitehead, C.; McQueen-Mason, S.J.; et al. Disrupting the cinnamyl alcohol dehydrogenase 1 gene (BdCAD1) leads to altered lignification and improved saccharification in Brachypodium distachyon. Plant J. 2012, 73, 496-508. [CrossRef]

40. Zhang, L.; Wang, G.; Chang, J.; Liu, J.; Cai, J.; Rao, X.; Zhang, L.; Zhong, J.; Xie, J.; Zhu, S. Effects of 1-MCP and ethylene on expression of three CAD genes and lignification in stems of harvested Tsai Tai (Brassica chinensis). Food Chem. 2010, 123, 32-40. [CrossRef]

41. Ma, D.; Xu, C.; Alejos-Gonzalez, F.; Wang, H.; Yang, J.; Judd, R.; Xie, D.Y. Overexpression of Artemisia annua cinnamyl alcohol dehydrogenase increases lignin and coumarin and reduces artemisinin and other sesquiterpenes. Front. Plant Sci. 2018, 9, 828. [CrossRef]

42. Guo, M.; Zhang, Y.; Meng, Z.; Jiang, J. Optimization of factors affecting Agrobacterium-mediated transformation of Micro-Tom tomatoes. Genet. Mol. Res. 2012, 11, 661-671. [CrossRef]

43. Murashige, T.; Skoog, F. A revised medium for rapid growth and bioassays with tobacco tissue cultures. Physiol. Plant. 1962, 15, 473-497. [CrossRef]

44. Weigel, D.; Glazebrook, J. Transformation of Agrobacterium using the freeze-thaw method. Cold Spring Harb. Protoc. 2006, 2006, 1031-1036. [CrossRef]

45. Livak, K.J.; Schmittgen, T.D. Analysis of relative gene expression data using real-time quantitative PCR and the $2^{-\triangle \Delta C T}$ Method. Methods 2001, 25, 402-408. [CrossRef]

46. Dyckmans, J.; Flessa, H.; Brinkmann, K.; Mai, C.; Polle, A. Carbon and nitrogen dynamics in acid detergent fibre lignins of beech (Fagus sylvatica L.) during the growth phase. Plant Cell Environ. 2002, 25, 469-478. [CrossRef]

47. Cai, C.; Xu, C.; Li, X.; Ferguson, I.; Chen, K. Accumulation of lignin in relation to change in activities of lignification enzymes in loquat fruit flesh after harvest. Postharvest Biol. Technol. 2006, 40, 163-169. [CrossRef]

48. González-Reyes, J.A.; Villalba, J.M.; Moyano, E.; Caballero, J.L.; Muñoz-Blanco, J. Cloning, expression and immunolocalization pattern of a cinnamyl alcohol dehydrogenase gene from strawberry (Fragaria $x$ ananassa cv. Chandler). J. Exp. Bot. 2002, 53, 1723-1734.

Sample Availability: Not available. 